\title{
REDUCCIÓN DE LA TURBIDEZ DEL AGUA USANDO COAGULANTES NATURALES: UNA REVISIÓN
}

\section{REDUCTION OF WATER TURBIDITY USING NATURAL COAGULANTS: A REVIEW}

\begin{abstract}
Luis Guzmán ${ }^{1}$, Ángel Villabona ${ }^{2}$, Candelaria Tejada ${ }^{3}$, Rafael García ${ }^{4}$
${ }^{1}$ Docente Universidad de Cartagena. Ingeniero de Alimentos. Especialista en Ingeniería Sanitaria y Ambiental, Universidad de Cartagena, Facultad de Ingeniería. Campus de Zaragocilla-Piedra de Bolívar. Cartagena - Bolívar. Colombia. lguzmanc1@ unicartagena.edu.co; ${ }^{2}$ Docente Universidad de Cartagena. Ingeniero Químico. Especialista en Ingeniería Sanitaria y Ambiental, Candidato a Magister en Ingeniería Ambiental, Universidad de Cartagena Campus de Zaragocilla-Piedra de Bolívar. Cartagena - Bolívar. Colombia. angelvillabona@yahoo.es; ${ }^{3}$ Docente Universidad de Cartagena. Ingeniero Químico. Magister en Educación Universidad del Norte, Candidata a Magister en Ingeniería Ambiental, Universidad de Cartagena Campus de Zaragocilla-Piedra de Bolívar. Cartagena - Bolívar. candelariatejada@yahoo.com; ${ }^{4}$ Instructor SENA. Licenciado en Biología. Especialista en Ingeniería Ambiental y Sanitaria, Universidad de Cartagena.
\end{abstract}

Rev. U.D.C.A Act. \& Div. Cient. 16(1): 253 - 262, 2013

\section{RESUMEN}

La coagulación es el proceso más importante en el tratamiento convencional del agua. Su aplicación incluye la remoción de especies en suspensión, mediante la adición de coagulantes químicos, cuyo uso trae desventajas asociadas a altos costos de adquisición, producción de grandes volúmenes de lodo y el hecho de que afectan el $\mathrm{pH}$ del agua tratada. Por lo expuesto anteriormente, se hace necesario la búsqueda de alternativas que incluyan la utilización de coagulantes de origen vegetal, entre otras. Este trabajo tuvo como propósito realizar una revisión bibliográfica acerca del uso de los coagulantes naturales de origen vegetal, utilizados en la remoción de turbidez en procesos de tratamiento de aguas y dar a conocer otros aspectos importantes, como su clasificación, su eficiencia y sus mecanismos de coagulación, empleados por cada uno de los materiales naturales estudiados. Como resultado, se encontró que todos los extractos de origen vegetal reportados son eficientes en la remoción de la turbidez del agua, producen menor cantidad de lodos y su principal mecanismo de coagulación utilizado es la adsorción y la neutralización de cargas.

Palabras clave: Coagulantes vegetales, turbidez, mecanismos de coagulación, tratamiento de agua.

\section{SUMMARY}

Coagulation is the most important process in conventional water treatment. The application includes the removal of species in suspense by means of addition of chemical coagu- lants, which involves correlated disadvantages associated to high acquisition costs, production of large mud volumes and the fact, that they affect, significantly, the $\mathrm{pH}$ of the processed water. Therefore, the search of alternatives that include the utilization of coagulants of vegetal origin, between others, becomes necessary. The purpose of the present research was a literature review related to the use of natural coagulants of vegetal origin, employed in the removal of turbidity in water treatment processes and to provide important aspects on classification, efficiency and mechanisms of coagulation of each of the studied materials. As results it was found that all reported extracts of vegetal origin are efficient in the removal of the water cloud, they produce smaller quantity of mud, and that the main mechanism of coagulation is adsorption and neutralization of loads.

Key words: vegetal coagulants, turbidity, coagulation mechanisms, water treatment.

\section{INTRODUCCIÓN}

El agua denominada "potable", debe ser aceptable desde el punto de vista estético, es decir, estar exenta de turbidez, de color y de sabor perceptibles, y debe tener una temperatura razonable. Las aguas naturales raramente son de calidad satisfactoria para el consumo humano o el uso industrial y casi siempre deben ser tratadas (Kiely, 1999).

El procesamiento del agua cruda contempla un tratamiento fisicoquímico, conocido como coagulación y floculación. La coagulación, se define como la adición de sustancias 
químicas y la provisión de mezcla, para que las partículas y algunos contaminantes disueltos se aglutinen en partículas más grandes que se puedan retirar mediante procesos de remoción de sólidos (Dempsey, 2006). Su aplicación incluye la remoción de especies químicas disueltas y la turbiedad del agua por adición de coagulantes químicos convencionales; además, la coagulación/floculación es un paso fundamental en el proceso de tratamiento del agua, no solamente porque remueve las partículas responsables de la turbiedad producida por las partículas suspendidas y por el material coloidal, sino porque también remueve los microorganismos que, a menudo, se adhieren a las partículas (McCarthy \& Zachara 1989; Antov et al. 2010); sin embargo, existen desventajas asociadas al uso de estos coagulantes, como altos costos de adquisición, producción de grandes volúmenes de lodo y el hecho que afectan significativamente el pH del agua tratada (Yin, 2010; Haaroff \& Cleasby 1988). También existe evidencia que relaciona a los coagulantes, a base de aluminio, con el desarrollo de la enfermedad de Alzheimer en los seres humanos, debido a la presencia de aluminio residual en el agua tratada (Flaten, 2001; Miller et al. 1984).

El uso de coagulantes a base de plantas para el tratamiento de aguas turbias data de varios milenios (Sanghi et al. 2002) $\mathrm{y}$, hasta ahora, los científicos medioambientales han podido identificar varios tipos de plantas, para este propósito. El empleo de materiales naturales puede minimizar o evitar la importación de los coagulantes químicos (Yin, 2010).

El objeto de esta revisión es el de dar a conocer aspectos relevantes de los coagulantes naturales, como su clasificación, su eficiencia y sus mecanismos de remoción, entre otros. Además, presentar recomendaciones y conclusiones de los principales hallazgos encontrados respecto a las ventajas del uso de los coagulantes naturales. La metodología aplicada fue de tipo cualitativo exploratoria, en donde se realizó una investigación documental, para la cual, se empleó, como técnica, la observación documental y, como instrumento, una matriz de análisis o de registro, que incluyó criterios como: coagulante natural utilizado, turbidez inicial, porcentaje de remoción de turbidez, dosis óptima de coagulante, autores y año.

\section{FUNDAMENTACIÓN TEÓRICA}

Las impurezas presentes en las fuentes de agua, se pueden clasificar según el tamaño, como:

I. Sólidos suspendidos (mayores a $10^{-6} \mathrm{~m}$ ): de origen mineral (arena, arcillas, entre otros) u orgánicos (producto de la descomposición de plantas y animales). Además, microorganismos como bacterias, plancton, algas y virus. Los sólidos suspendidos son responsables de la turbidez y el color del agua (Vargas \& Romero, 2006).
II. Partículas coloidales (entre $10^{-6}$ y $10^{-9} \mathrm{~m}$ ): son sólidos suspendidos originados, de igual manera que los anteriores, pero con un tamaño inferior y una velocidad de sedimentación muy lenta. Son responsables de turbidez y del color (Vargas \& Romero, 2006). Estas partículas están, por lo general, cargadas negativamente, debido a la presencia de grupos $\mathrm{RCOO}^{-}$y OH . La carga negativa en la superficie causa repulsión entre las partículas, evitando la aglomeración y la formación de partículas más grandes que sedimentarían fácilmente.

III. Sustancias disueltas (menores de $10^{-9} \mathrm{~m}$ ); son usualmente sustancias inorgánicas, como cationes y aniones y sustancias orgánicas, como ácidos, alcoholes y aldehídos, entre otros. También puede haber gases presentes (Vargas \& Romero, 2006).

\section{PRINCIPALES COAGULANTES}

Coagulantes metálicos: Han sido los más utilizados para el tratamiento del agua cruda, poseen la capacidad de actuar como coagulantes y floculantes y, cuando son disueltos, forman compuestos complejos hidratados. Entre los más utilizados se hallan: sulfato de aluminio, sulfato férrico, sulfato ferroso, cloruro férrico y el aluminato de sodio (Romero, 2000).

Polielectrólitos: Son polímeros orgánicos sintéticos de gran tamaño molecular, con carga eléctrica neta; son muy eficaces en un amplio rango de $\mathrm{pH}$ y, debido a su alto costo, se utilizan junto con coagulantes metálicos. Se clasifican según su carga en: Catiónicos, con carga positiva: al entrar en contacto con el agua forman aniones, que permiten remover las partículas de carga negativa y son más eficaces a pH bajo; Aniónicos, que tienen carga negativa: al entrar en contacto con el agua forman cationes, que permiten remover las partículas de carga positiva y son más eficaces a $\mathrm{pH}$ alto y No iónicos, son neutros: al entrar en contacto forman iones positivos y negativos, pero se necesitan dosis mayores en comparación con los anteriores para obtener resultados similares.

Coagulantes Naturales: Son una fuente alternativa con gran potencial aún no explotado suficientemente; se producen de manera espontánea, debido a reacciones bioquímicas que ocurren en animales y en plantas. Por lo general, presentan una mínima o nula toxicidad y, en muchos casos, son productos alimenticios con alto contenido de carbohidratos y de proteínas solubles en agua (Lee et al. 1995; Ganjidoust et al. 1997). Algunos de ellos tienen propiedades coagulantes o floculantes que actúan de modo similar a los coagulantes sintéticos, aglomerando las partículas en suspensión que contiene el agua cruda, facilitando su sedimentación y reduciendo la turbidez inicial; en muchos lugares son utilizados 
en forma empírica por nativos para aclarar el agua turbia, con muy buenos resultados (Yin, 2010).

Mecanismos de la coagulación y de la floculación: Se denomina coagulación-floculación al proceso por el cual las partículas se aglutinan en pequeñas masas, con peso específico superior al del agua, llamadas flóculos. Dicho proceso, se usa para: (a) remoción de turbiedad orgánica o inorgánica que no puede sedimentar rápidamente; (b) remoción de color verdadero y aparente; (c) eliminación de bacterias, virus y organismos patógenos susceptibles de ser separados por coagulación; (d) destrucción de algas y plancton en general y, (e) eliminación de substancias productoras de sabor y de olor en algunos casos y de precipitados químicos suspendidos o compuestos orgánicos en otros (Arboleda, 1992).

En general, la coagulación es un proceso donde el potencial repulsivo de la doble capa eléctrica del coloide es reducido, de tal manera, que se pueden producir micro-partículas. Estas micro-partículas chocan con otras y forman estructuras más grandes (flóculos) en el proceso de floculación (Matilainen et al. 2010).

La remoción de turbidez y de organismos en los suministros de agua involucra la eliminación de impurezas que están cargadas negativamente a niveles de $\mathrm{pH}$ natural y han formado una dispersión estabilizada (Bolto, 1995). Las partículas se pueden agregar y se pueden asentar en la solución, a través de cuatro mecanismos básicos: a) compresión de la doble capa; b) coagulación por barrido; c) adsorción y neutralización de carga y, d) adsorción y unión interpartículas (Crittenden et al. 2005; Miller et al. 2008; Bolto \& Gregory, 2007).

Los coagulantes poliméricos están asociados con los mecanismos (c) y (d) con estructuras de cadena larga, incrementando el número de sitios de adsorción desocupados. Parece que estos dos mecanismos proporcionan los principios básicos del funcionamiento interno de los coagulantes vegetales (Yin, 2010).

\section{MATERIALES NATURALES VEGETALES UTILIZADOS COMO COAGULANTES}

La mayoría de los extractos naturales se derivan de semillas, de hojas, de cortezas o savia, de raíces y de frutas, extraídos de árboles y de plantas (Pritchard et al. 2009). Los polímeros orgánicos naturales se han usado por más de 4000 años en India, en África y en China como coagulantes eficientes y como ayudantes de coagulación de aguas con alta turbidez, para uso doméstico en áreas rurales (Asrafuzzaman et al. 2011). En esas regiones, se han usado plantas nativas, como las semillas del árbol de Nirmali - Strychnos potatorum, granos tostados de maíz (Zea mays) o savia del cactus Opuntia ficus indica (Šćiban et al. 2005). Esos coagulantes naturales, se pueden usar sólos o como substitutos de coagulantes y de floculantes químicos (Özacar \& Sengil, 2003) y se aplican para reducir la turbidez y los microorganismos en aguas (Ghebremichael et al. 2005), para el ablandamiento de aguas (Muyubi \& Evinson, 1995) y para el acondicionamiento de lodos (Özacar \& Sengil, 2000).

Yongabi (2004) reportó haber probado la capacidad coagulante y desinfectante de la Moringa oleifera, Jatropha curcas (Piñón Mejicano), Pleurotus tuberregium sclerotium (Hongo) y Hibiscus sabdariffa (Rosa de Jamaica), comparándolas con el alumbre en muestras de aguas residuales. Śćiban et al. (2005) informaron acerca de "plantas recientemente ensayadas", como coagulantes: frijol mezquite (Prosopis juliflora) y Cactus latifaria, en Venezuela; en Egipto y en el norte de Sudán, varios tipos de frijoles, de alverjas, de cacahuates y de lupinos, semillas de Cassia angustifolia y semillas de M. oleífera.

Antov et al. (2007) estudiaron la actividad coagulante de extractos de semillas del frijol común (Phaseolus vulgaris), utilizando soluciones salinas como medio de extracción, a diferentes concentraciones. Reportan haber obtenido valores altos en concentración de proteína y actividades de coagulación, cercanas al $40 \%$ en el extracto crudo, cuando utilizaron $0,5 \mathrm{~mol} / \mathrm{L}$ de $\mathrm{NaCl}$, demostrando que la purificación de las proteínas extraídas de las semillas del frijol común tiene características de coagulantes naturales.

Fernández et al. (2008) evaluaron el exudado gomoso de la Cassia siamea (goma guar); para ello emplearon agua turbia sintética, con valores de turbidez de 10; 15; 25; 50; 75 y 100 NTU. Los niveles de turbiedad finales alcanzados estuvieron entre 2 - 4 NTU, para una dosis óptima de $50 \mathrm{mg} / \mathrm{L}$ y disminuciones en el color, hasta valores de 5 UC, con aplicación de 10 - 20mg/L de la goma.

Pritchard et al. (2009) informan que se han adelantado estudios sobre el desempeño como coagulantes de los extractos de plantas, como el árbol de nirmali (S. potatorum), de tamarindo (Tamerindous indica), de guar (Cyamopsis psoraloides), de red sorella (Hibiscus sabdariffa), de fenugreco o alholva (Trigonella foenum) y de lentejas (Lens esculenta), usando agua cruda, con turbiedad en los rangos de 50 a 750 NTU (Schultz \& Okun, 1992).

\section{OTROS MATERIALES VEGETALES USADOS COMO COAGULANTES}

Taninos: Tradicionalmente, se han usado para el curtido de pieles, pero varios de ellos también se han empleado como floculantes. Su origen natural es como metabolitos secundarios de plantas, encontrándose en cortezas, en frutos y en hojas; las cortezas de la Acacia y la Schinopsis constituyen el principal recurso para la industria marroquinera, las de otros 
árboles no tropicales, como el Quercus ilex, Q. suber y Q. robur, el Castanea y el Pinus también son ricos en taninos (Beltrán et al. 2010). En este contexto, los taninos catiónicos pueden ser el recurso de nuevos agentes de coagulación. A escala experimental, se ha demostrado que es posible sintetizar coagulantes derivados de los taninos a partir de varias materias primas: Acacia mearnsii, Sch. balansae, $P$. pinaster, C. sativa, a través de un procedimiento simple, que involucra la reacción de Mannish (Beltrán et al. 2011).

La cationización de los taninos, se conoce como un procedimiento que confiere carácter catiónico a la matriz orgánica del tanino (Beltrán et al. 2011), ya que los agentes cargados positivamente pueden desestabilizar coloides aniónicos, una vez se mezclan en soluciones acuosas. La desestabilización y la sedimentación subsiguientes provocan la remoción de una amplia variedad de sustancias aniónicas, tales como colorantes, tensoactivos o materia orgánica (Beltrán et al. 2010).

Graham et al. (2008) investigaron un polímero catiónico comercial a base de taninos (TBP), con el objeto de establecer sus propiedades químicas básicas y su comportamiento como coagulante. El mecanismo de coagulación sugerido es la desestabilización de las partículas de caolín por neutralización de cargas.

Šćiban et al. (2009) utilizaron extractos de diferentes semillas: "Horse chestnut" (Aesculus hyppocastanum), roble común $(Q$. robur), roble turco $(Q$. cerris), roble rojo norteño (Q. ruber) y castañea europea (C. sativa). A cada uno de los extractos les determinaron contenido de proteínas y su actividad coagulante, encontrando que la castaña europea y el roble común son las más eficientes.

Jeon et al. (2009) emplearon extracto etanólico de semilla de uvas (GSE) y polifenoles derivados de las semillas, como ácido tánico y la catequina, en un esfuerzo por encontrar nuevos coagulantes orgánicos naturales (NOCs).

Yin (2010) y Özacar \& Sengil (2003) estudiaron la aplicación del tanino como coagulante autónomo o como ayuda de coagulación, para el tratamiento de agua. El tanino usado en su estudio, se extrajo de la Valonia. Ellos concluyen que ese tanino combinado con el sulfato de aluminio es un excelente sustituto de los coagulantes químicos.

Trabajos con extractos de los taninos de Sch. balansae y A. mearnsii, disponibles en tres productos comerciales (Clarotan, Weibull Black y Quebracho colorado) y en tres compuestos tipo amina (cloruro de amonio, cloruro de glicidiltrimetilamonio y dietanolamina), mostraron que el producto óptimo es el Clarotan y, además, la dietanolamina (Beltrán et al. 2010).
Sánchez et al. (2010a) ensayaron cuatro tipos de agua (agua superficial, agua residual municipal, aguas residuales de industria textil y aguas residuales de lavandería) y como agente coagulante TANFLOC (extracto de mimosa modificado). El resultado obtenido fue la remoción de turbidez del agua superficial entre 50-60\%, con una dosis de 2mg/L. Sánchez et al. (2010b) analizaron el coagulante SILVAFLOC, un producto a base de taninos, el cual, se modificó mediante proceso fisicoquímico. Ellos reportan una remoción de turbidez del $90 \%$, con una dosis de $20 \mathrm{mg} / \mathrm{L}$.

Beltrán et al. (2011) reportaron un nuevo agente coagulante, a partir del extracto del tanino crudo de la A. mearnsii, $\mathrm{NH}_{4} \mathrm{Cl}$ y formaldehido. Como resultados, apreciaron diferencias evidentes en la eficiencia de la remoción. Respecto de la remoción de turbidez, encontraron que a bajas dosis de coagulante $(12,5-25 \mathrm{mg} / \mathrm{L})$ es posible remover la casi totalidad de la turbidez inicial de las muestras.

Cactus: El género Opuntia (familia Cactaceae), se caracteriza por la producción de un hidrocoloide, conocido como mucílago, el cual, forma redes moleculares que pueden retener grandes cantidades de agua (Saag et al. 1975). Los mucílagos son substancias poliméricas complejas de naturaleza carbohidrato, con una estructura altamente ramificada (Medina et al. 2000; Goycoolea \& Cárdenas, 2004; Matsuhiro et al. 2006), que contiene proporciones variables de L-arabinosa, D-galactosa, L-ramnosa y D-xilosa, así como ácido galacturónico en diferentes proporciones (Trachtenberg \& Mayer, 1981). Su estructura, se propone como dos fracciones distintas solubles en agua: una, una pectina, con propiedades gelificantes, $y$, la otra, un mucilago sin propiedades gelificantes (Goycoolea \& Cárdenas, 2004).

Miller et al. (2008) estudiaron las propiedades coagulantes de Opuntia spp., que se evalúa por primera vez, en la eliminación de la turbidez de muestras de agua sintéticas y dieron los pasos necesarios para aclarar el mecanismo de la coagulación subyacente. Las Opuntia spp. redujeron la turbidez en un $98 \%$, con respecto a un rango de turbidez inicial. Se sugiere que opera predominantemente, a través de un mecanismo de coagulación de puente.

Yan et al. (2008) trabajaron con Opuntia, evaluando la eficacia de dicho coagulante para la eliminación de turbidez en aguas superficiales (estuarios y ríos). Los valores de la turbidez inicial fueron de 499 NTU y 547 NTU. Luego del tratamiento obtuvieron remociones del $98 \%$ (estuario) y $70 \%$ (rio). Se compararon los resultados con aquellos obtenidos por Zhang et al. (2006), quienes obtuvieron 99\% como la más alta eficiencia de remoción, comparativamente similar a la obtenida, para aguas de estuario. 
Fuentes et al. (2011) evaluaron la efectividad de un coagulante extraído del cardón Stenocereus griseus en la potabilización del agua. Para ello, prepararon soluciones diluidas con turbiedades entre 20 y 100 NTU. Después de aplicar las dosis del coagulante, los porcentajes de remoción de turbidez oscilaron entre 14,50 y $80,42 \%$, antes de la simulación de la filtración y entre 69,27 y 96,46\%, luego de ello, demostrando la efectividad del coagulante extraído de St. griseus en la potabilización de agua.

Moringa oleífera: La M. oleifera (Horseradish, Drumstick tree o Miracle tree) es una planta tropical no-tóxica (a bajas concentraciones), que se encuentra a lo largo de la India, de Asia, de África sub-sariana y de América Latina (Sanghi et al. 2002), cuyas semillas contienen un aceite comestible y una sustancia soluble en agua (Ndabigengesere et al. 1995); es indiscutiblemente el coagulante natural más estudiado por la comunidad científica medioambiental. Se ha informado que las comunidades rurales en los países africanos utilizan los extractos de semilla crudos para aclarar el agua turbia.

Gassenschmidt et al. (1995) informan que el agente coagulante es una proteína con una masa molecular de $6,5 \mathrm{kDa}$, mientras Ghebremichael et al. (2005) sugieren que es una proteína catiónica, con una masa molecular menor de 6,5kDa. Recíprocamente, para Okuda et al. (2001), el componente activo no es una proteína, polisacárido o lípido, sino un polielectrolito orgánico, con un peso molecular de aproximadamente 3,0kDa. Aunque algunos grupos de investigadores parecen estar de acuerdo que el agente activo es una proteína catiónica.

El primer escrito de Ndabigengesere et al. (1995) elucida, comprensivamente, los mecanismos de la coagulación básicos inherentes a la $M$. oleífera. Sugiere que sus agentes activos coagulantes son las proteínas cationicas diméricas y su principal mecanismo de coagulación la adsorción y la neutralización de carga.

En muchos casos, las partículas de impurezas están cargadas negativamente y los polielectrolitos catiónicos son los coagulantes más eficaces, que predicen el uso de la Moringa, como agente de coagulación (Bolto \& Gregory, 2007). Su capacidad coagulante, se puede reforzar más allá por la adición de cationes. En un estudio dirigido por Okuda et al. (2001), se establece que los cationes bivalentes (por ejemplo $\mathrm{Ca}^{2+}$ y $\mathrm{Mg}^{2+}$ ) refuerzan, significativamente, el efecto coagulante de los extractos, en la cual, los cationes pueden tener adsorbido los componentes activos para formar una red estructural insoluble para capturar las partículas suspendidas de caolín.

Santos et al. (2009) investigaron la actividad aglutinante de la lectina extraída de diferentes tejidos de la $M$. oleífera; las preparaciones de lectina ( $\mathrm{cMoL}$ ) mostraron actividad coagulante, similar al sulfato de aluminio. El ensayo de la actividad coagulante, se basó en el método descrito por Ghebremichael et al. (2005). Para ello, prepararon soluciones con alta (250-300 NTU) y media (125-150 NTU) turbidez. Afirman, que las preparaciones de lectina tienen actividad coagulante en aguas con alta y con media turbidez.

La capacidad de remoción de dos extractos de proteínas coagulantes de la M. oleífera obtenidos en solución salina, utilizando agua de río, induciendo la turbidez con caolín (turbidez inicial fue de 170 NTU), la compararon Sánchez et al. (2010b). De su estudio, se tiene que la dosis óptima está cerca a $0,5 \mathrm{mg} / \mathrm{L}$ y que la turbidez final del extracto de un sólo paso es casi dos veces más alta, que la turbidez obtenida con el extracto de dos pasos.

Pritchard et al. (2010) adelantaron un proyecto de investigación, con el fin de observar la actuación de la M. oleifera comparada con el sulfato de aluminio y el sulfato férrico. Para ello, usaron un agua modelo sembrada con E. coli y una turbidez de 146 NTU, creada artificialmente con caolín; aguas crudas de diferentes fuentes, agua de río, con una turbidez < 5 NTU; otra con turbidez de 45 NTU y agua híbrida, una mezcla de los dos tipos de agua. Los resultados mostraron que la $M$. oleifera removió el $84 \%$ de turbiedad y el $88 \%$ de $E$. coli, en el agua modelo; en el agua de río de baja turbidez ( $<5$ NTU), los resultados mostraron una reducción de E. coli, del $82 \%$, para la M. oleifera. En agua turbia de río de 45 NTU la remoción de turbidez fue de $76 \%$ y una reducción de $E$. coli del $93 \%$, con M. oleifera.

Asrafuzzaman et al. (2011) estudiaron el uso de la M. oleifera, Cicer arietinum (garbanzo o chícharo) y Dolichos lablab (poroto o judía) como coagulantes naturales, para reducir la turbidez de agua sintética. En el caso específico de la M. oleífera, las dosis usadas fueron 50, 60, 70, 80, 90 y $100 \mathrm{mg} / \mathrm{L}$; la turbidez del agua utilizada, se tomó como agua de alta turbidez (100 NTU), media turbidez (48 NTU) y baja turbidez (25 NTU). La turbidez fue medida antes y después del tratamiento. Ellos concluyeron que la $M$. oleifera tiene un mejor desempeño en aguas de alta turbidez que en aguas con turbidez media o baja.

Almidón: Es un polímero de $\alpha$-glucosa, en el que los monómeros se encuentran unidos por enlaces 1-4 y, ocasionalmente, se ramifican, formando un enlace adicional en posición 1-6. Es la forma principal en la que se almacena el carbohidrato en los tejidos de la mayoría de las especies vegetales superiores y se acumula en las hojas de las plantas y en tejidos no fotosintéticos, especialmente, los implicados en la reproducción, tales como semillas, frutos y tubérculos.

El almidón, además de ser consumido como tal, se puede 
someter a una variedad de procedimientos de transformación que cambian sus propiedades funcionales y lo convierten en estabilizante, emulgente y gelificante.

En Colombia, se han realizado investigaciones sobre la utilización de coagulantes naturales, como el almidón de yuca y el de maíz, los cuales, han sido evaluados junto con el sulfato de aluminio B y un polielectrólito comercial, como agentes coagulantes de aguas crudas superficiales. Los resultados obtenidos mostraron un buen desempeño del almidón de maíz, comparable con el polielectrólito y mejor que el sulfato de aluminio B; por el contrario, el almidón de yuca presentó un mal desempeño en estas condiciones y fue el menos efectivo de los agentes coagulantes evaluados (Rodríguez et al. 2007)

Antov et al. (2010) utilizaron extractos del frijol común ( $P h$. vulgaris) y reportan que las semillas son una fuente potencial de coagulante. El objetivo del estudio fue la purificación parcial de los componentes activos de coagulación extraídos de la semilla del frijol común (CBS) y concluyen que el extracto purificado del CBS tiene una capacidad coagulante 22 veces mayor que la del extracto crudo.

Samanea saman: González et al. (2006) estudiaron el exudado gomoso de $S$. saman como coagulante natural, estableciendo su dosis óptima, mediante la prueba de jarras y determinando los parámetros de turbidez, color, $\mathrm{pH}$, alcalinidad total, número más probable y conteo de heterótrofos, usando para ello, agua turbia sintética inoculada con un cultivo puro de $E$. coli y solución de coagulante en dosis de $10-500 \mathrm{mg} / \mathrm{L}$, con valores de turbidez inicial entre $10-100$ NTU. La dosis óptima del coagulante resultó entre $10-25 \mathrm{mg} /$ $\mathrm{L}$, obteniendo disminuciones significativas en los valores de turbidez (1 NTU) y color (5 UC), demostrando así la eficiencia de este coagulante natural.

Algas: El agar o agar-agar es un polisacárido que se obtiene de algas del género Gelidium, algas que se han utilizado en la cocina tradicional japonesa, por sus propiedades gelificantes, desde hace muchos siglos. El agar se considera formado por la mezcla de dos tipos de polisacáridos: la agarosa y la agaropectina. La agarosa y la agaropectina, se diferencian por la presencia de restos de sulfato y de piruvato, relativamente abundantes en la agaropectina y muy escasos (idealmente, ausentes) en la agarosa. Existe una gradación de tipos entre la agarosa y la agaropectina muy sulfatada. Precisamente, las algas sintetizan el agar en forma sulfatada, produciéndose la anhidrogalactosa en la eliminación enzimática del sulfato.

Prado et al. (2011) reportaron haber trabajado con la agarosa catiónica con diferentes grados de substitución (DS), preparada por reacción de la agarosa comercial, con 3-clo- ro-2-cloruro de hidroxipropiltrimetilamonio (CHPTAC) y evaluaron, por primera vez, su rendimiento floculante, empleando suspensiones de caolín, como sistemas modelo. Para esta prueba usaron cuatro agarosas cationizadas con diferentes grados de substitución: CAG04 (DSEA=0.04), CAG19 (DSEA=0.19), CAG58 (DSEA=0.58) y CAG77 (DSEA=0.77) y se adicionaron a una agua con turbidez inicial de 100 NTU. Como resultado de la floculación, encontraron que la turbidez residual, luego de $15 \mathrm{~min}$ (fin de la prueba), era de 25 NTU para una dosis óptima de $2-4 \mathrm{mg}$ del agente floculante CAG04 y CAG19 por gramo de caolín.

En la tabla 1, se relacionan los coagulantes naturales catiónicos, aniónicos y no iónicos evaluados y considerados positivos en la reducción de turbidez. De lo anterior, se puede destacar que diferentes autores reportan a la especie $M$. oleifera, con un porcentaje de remoción, que oscila entre el 94 y el $96 \%$, lo que la coloca en primer lugar en cuanto a desempeño como coagulante natural respecto a las otras especies evaluadas, seguida de las diferentes variedades de opuntia, cuyos porcentajes de remoción están en el rango del 90 - 92\%. También, se destaca el excelente desempeño del Tanfloc (coagulante a base de taninos), que presenta una remoción del $100 \%$, aumentando la dosis de coagulante y disminuyendo la turbidez inicial. La desventaja que se destaca es que no muchos investigadores han reportado el uso de esta especie. Por último, sobresale que los materiales vegetales que muestran los mejores desempeños y sobre los cuales se ha investigado ampliamente son los de carácter catiónico.

\section{CONCLUSIONES}

Algunas ventajas del uso de los coagulantes naturales, en comparación con el alumbre $\left(\mathrm{KAl}\left(\mathrm{SO}_{4}\right)_{2} \cdot 12 \mathrm{H}_{2} \mathrm{O}\right)$, en el tratamiento del agua son:

- Bajos requerimientos en la dosis del coagulante, volumen reducido en producción de lodo, reducido aumento en la carga iónica del agua tratada y economías en el costo entre $25-30 \%$.

- Todos los extractos, de origen vegetal, ensayados y reportados por la literatura son eficientes en la remoción de turbidez del agua, comparados con el sulfato de aluminio.

- La adición de coagulantes naturales, como ayudas de coagulación, reducen significativamente la dosis del coagulante sulfato de aluminio.

- Los lodos producidos en el tratamiento de aguas crudas reportados por la literatura son biodegradables. 
Tabla 1. Productos naturales evaluados y considerados positivos para reducir la turbidez.

\begin{tabular}{|c|c|c|c|c|}
\hline MATERIAL VEGETAL & $\begin{array}{l}\text { TURBIDEZ } \\
\text { INICIAL } \\
\text { (NTU) } \\
\end{array}$ & $\begin{array}{l}\text { EFICIENCIA DE } \\
\text { REMOCIÓN (\%) }\end{array}$ & $\begin{array}{l}\text { DOSIS ÓPTIMA } \\
(\mathrm{mg} / \mathrm{L})\end{array}$ & REFERENCIA \\
\hline $\begin{array}{l}\text { Coagulantes aniónicos } \\
\text { Nirmali (Strychnos potatorum) }\end{array}$ & $\begin{array}{l}18-21 ; 38 \\
-42 ; 130- \\
135\end{array}$ & $83-88$ & $1,0-2,0$ & \multirow{2}{*}{ Babu \& Chaudhuri, 2005} \\
\hline $\begin{array}{l}\text { Coagulantes catiónicos } \\
. \quad \text { Moringa oleifera }\end{array}$ & $\begin{array}{l}18-21 ; 38 \\
-42 ; 130- \\
135\end{array}$ & $94,0-99,0$ & $100-200$ & \\
\hline $\begin{array}{l}\text { Amorpha fruticosa (Falso Indigo } \\
\text { Bush) } \\
\end{array}$ & 17,$5 ; 30 ; 70$ & 80; 70; 80 & $5 ; 5 ; 10$ & \multirow{4}{*}{ Šćiban et al. 2005} \\
\hline · Ceratonia siliqua (Carob) & 17,$5 ; 30 ; 70$ & $100 ; 80 ; 80$ & $20 ; 10 ; 10$ & \\
\hline $\begin{array}{l}\text { Robinia pseudoacacia (Black } \\
\text { Locust) }\end{array}$ & 17,$5 ; 30 ; 70$ & $60 ; 60 ; 60$ & $5 ; 10 ; 10$ & \\
\hline $\begin{array}{l}\text { Phaseolus vulgaris } \\
\text { (Cargamanto) }\end{array}$ & 17,$5 ; 30 ; 70$ & $80 ; 60 ; 65$ & $5 ; 10 ; 10$ & \\
\hline . Cactaceous opuntia & 176 & 90 & $30-50$ & Zhang et al. 2006 \\
\hline $\begin{array}{l}\text { Polímero catiónico a base de } \\
\text { Tanino (TBP) pH entre } 4,0 \text { y } 7,0\end{array}$ & 100 & 85 & $0,15-0,30$ & Graham et al. 2008 \\
\hline $\begin{array}{l}\text { Acacia siamea (exudado } \\
\text { gomoso) }\end{array}$ & $10-100$ & $80-95$ & 50 & Fernández et al. 2008 \\
\hline $\begin{array}{ll} & \text { Opuntia spp. } \\
\text {. } & \text { Moringa oleífera } \\
\end{array}$ & $\begin{array}{l}125 \\
125\end{array}$ & $\begin{array}{l}90-92 \\
90-92\end{array}$ & $\begin{array}{c}5-15 \\
15\end{array}$ & Miller et al. 2008 \\
\hline $\begin{array}{l}\text { Aesculus hyppocastanum } \\
\text { (Castaño) } \\
\text {. } \\
\text { Castanea sativa (Castaño } \\
\text { común) } \\
\text {. } \\
\text { - } \\
\text { Quercus robur (Roble común) } \\
\text { Quercus cerris (Roble turco) }\end{array}$ & $\begin{array}{l}70 ; 35 ; 17,5 \\
70 ; 35 ; 17,5 \\
70 ; 35 ; 17,5 \\
70 ; 35 ; 17,5 \\
70 ; 35 ; 17,5\end{array}$ & $\begin{array}{l}40-85 \\
40-85 \\
40-85 \\
40-85 \\
40-85 \\
\end{array}$ & $\begin{array}{l}0,5 \\
0,5 \\
0,5 \\
0,5 \\
0,5 \\
\end{array}$ & Šćiban et al. 2009 \\
\hline $\begin{array}{l}\text { - Moringa oleífera } \\
\text {. J. curcas } \\
\end{array}$ & $\begin{array}{l}49 \\
49 \\
\end{array}$ & $\begin{array}{l}96 \pm 2 \\
95 \pm 1\end{array}$ & $\begin{array}{l}250 \\
50\end{array}$ & Pritchard et al. 2009 \\
\hline $\begin{array}{l}\text { Schinopsis balansae } \\
\text { (Quebracho) } \\
\text { Acacia mearnsii (Acacia } \\
\text { Australiana) }\end{array}$ & $\begin{array}{l}123 \\
200\end{array}$ & $\begin{array}{c}80-95 \\
75\end{array}$ & $\begin{array}{l}0,25 \\
12,5\end{array}$ & $\begin{array}{l}\text { Beltrán et al. } 2010 \\
\text { Beltrán et al. } 2011\end{array}$ \\
\hline $\begin{array}{ll} & \text { Tanfloc (Coagulante a base de } \\
\text { taninos) } \\
\text { Tanfloc (Coagulante a base de } \\
\text { taninos) } \\
\text {. } \\
\text { Moringa oleífera } \\
\text { Silvafloc (Coagulante a base de } \\
\text { taninos) }\end{array}$ & $\begin{array}{l}100 \\
80 \\
80 \\
80 \\
\end{array}$ & $\begin{array}{c}50-60 \\
100 \\
95 \\
85 \\
\end{array}$ & $\begin{array}{l}2 \\
20 \\
20 \\
20\end{array}$ & $\begin{array}{l}\text { Sánchez et al. 2010a } \\
\text { Sánchez et al. 2010b }\end{array}$ \\
\hline $\begin{array}{l}\text { Phaseolus vulgaris (Fríjol } \\
\text { común) }\end{array}$ & 35 & 72.3 & $0,7-1,0$ & Antov et al. 2010 \\
\hline $\begin{array}{ll}\cdot & \text { Moringa. oleífera } \\
\text {. } & \text { Dolichos lablab } \\
& \text { Cicer arietinum } \\
\end{array}$ & $\begin{array}{l}90-120 \\
90-120 \\
90-120 \\
\end{array}$ & $\begin{array}{l}86,9 \\
84,5 \\
93,8\end{array}$ & $\begin{array}{l}50 \\
50 \\
50\end{array}$ & Asrafuzzaman et al. 2011 \\
\hline $\begin{array}{l}\text { Coagulantes no iónicos: } \\
\cdot \quad \text { Cyamopsis tetragonolobus } \\
\text { (Goma Guar) }\end{array}$ & 49 & $90 \pm 2$ & 50 & Pritchard et al. 2009 \\
\hline
\end{tabular}


- Los almidones catiónicos son coagulantes potenciales para remover algas comparados con los coagulantes inorgánicos. Además, requieren bajas dosis.

- Los coagulantes de taninos modificados presentan un buen rendimiento como coagulantes para la remoción de turbidez y color, comparados con el sulfato de aluminio.

- Los coagulantes orgánicos naturales (NOCs) se han caracterizado, ampliamente, por su potencial alternativa a los coagulantes metálicos en el tratamiento de agua.

\section{RECOMENDACIONES}

Por lo expuesto anteriormente, se hace necesario la formulación de proyectos de investigación para la búsqueda de alternativas, que incluyan la utilización de coagulantes de origen vegetal, que sean amigables con el medio ambiente e inocuas para la salud humana al ser utilizados en la remoción de turbidez, en procesos de tratamiento de aguas superficiales.

Se propone estudios más específicos a los reportados en el presente trabajo, para lograr una identificación química completa de los coagulantes naturales, extraídos de especies nativas de cada región.

Se recomienda la identificación y la clasificación botánica de plantas nativas con potenciales propiedades aglutinantes y seguidamente en proyectos subsiguientes investigar sobre la obtención del polímero natural proveniente de cada especie y su aplicación en el proceso de clarificación de agua en aguas sintéticas.

Realizar estudios de aplicación para aguas superficiales reales con alta turbiedad utilizando los polímeros naturales identificados en cada región geográfica, como coagulante y coadyuvante en el proceso de clarificación.

Conflicto de intereses: Este manuscrito fue preparado y revisado con la participación de todos los autores que en él aparecen, quienes declaramos que no existe ningún conflicto de intereses que pongan en riesgo la validez de los resultados acá presentados.

\section{BIBLIOGRAFÍA}

1. ANTOV, M.G.; ŠĆIBAN, M.B.; ADAMOVIĆ, S.R.; KLAŚNJA, M.T. 2007. Investigation of isolation conditions and ion-exchange purification of protein coagulation components from common bean seed. BIBLID: 1450-7188. 38:3-10.

2. ANTOV, M.G.; ŠĆIBAN, M.B.; PETROVIĆ, N.J. 2010. Protein from common bean (Phaseolus vulgaris) seed as a natural coagulant for potential application in water turbidity removal. Biores. Techn. 101:2167-2172.

3. ARBOLEDA VALENCIA, J. 1992. Teoría y Práctica de la purificación del agua. Ed. Acodal. Colombia. 72p.

4. ASRAFUZZAMAN, M.D.; FAKHURUDDIN, A.N.M.; ALAMGIR HOSSAIN, M.D. 2011. Reduction of turbidity of water using locally available natural coagulants. Int. Scholarly Res. Network. ISRN Microbiology. Article ID 632189. 6p.

5. BABU, R.; CHAUDHURI, M. 2005. Home water treatment by direct filtration with natural coagulant. J. Water Health. 3:27-30.

6. BELTRÁN-HEREDIA, J.; SÁNCHEZ-MARTÍN, J.; GÓMEZ-MUÑOZ, M.C. 2010. New coagulant agents from tannin extract: preliminary optimization studies. Chem. Eng. J. 162:1019-1025.

7. BELTRÁN-HEREDIA, J.; SÁNCHEZ-MARTÍN, J.; DÁVILA-ACEDO, M.A. 2011. Optimization of the synthesis of a new coagulant from a tannin extract. J. Haz. Mat. 186:1704-1712.

8. BOLTO, B.A. 1995. Soluble polymer in water purification. Prog. Polym. Sci. 20:987-1041.

9. BOLTO, B.; GREGORY, J. 2007. Organic polyelectrolytes in water treatment. Water Res. 41:2301-2324.

10. CRITTENDEN, J.C.; TRUSSELL, R.R.; HAND, D.W.; HOWE, K.J.; TCHOBANOGLOUS, G. 2005. Water treatment principles and design, $2^{\text {nd }}$ ed.; John Wiley and Sons, Inc.: Hoboken, New Jersey. 578p.

11. DEMPSEY, B. 2006. Coagulant characteristics and reactions. En: Newcombe, G.; Dixon, D. (Eds.) Interface Science in Drinking Water Treatment: Theory and Applications. Arthur Hubbard (Series Editor), Interface Science and Technology - Vol. 10, Elsevier, The Netherlands, 5p.

12. FERNÁNDEZ, A.; CHÁVEZ, M.; HERRERA, F.; MAS Y RUBI, M.; MEJIAS, D.; DÍAZ, A. 2008. Evaluación del exudado gomoso de Acacia siamea como coagulante en la clarificación de las aguas para consumo humano. Rev. Tec. Ing. U. Zulia. 31(Ed. Especial):32-40.

13. FLATEN, T.P. 2001. Aluminium as a risk factor in $\mathrm{Al}$ zheimer's disease, with emphasis on drinking water. Brain Res. Bull. 55:187-196. 
14. FUENTES, L.; MENDOZA, I.; ÁNGELA, S.; LÓPEZ, M.; CASTRO, M.; URDANETA, C. 2011. Efectividad de un coagulante extraído de Stenocereus griseus (Haw.) Buxb. en la potabilización del agua. Rev. Téc. Ing. U. Zulia. 1(34):48-56.

15. GANJIDOUST, H.; TATSUMI, K.; YAMAGISHI, T.; GHOLIAN, R.N. 1997. Effect of syntethic and natural coagulant on ligning removal from pulp and paper waste water. Water Sci. Techn. 35:286-291.

16. GASSENSCHMIDT, U.; JANY, K.K.; TAUSCHER, B.; NIEBERGALL, H. 1995. Isolation and characterization of a flocculation protein from Moringa oleifera Lam, BBA. Biochem. Biophys. Acta. 1243:477-481.

17. GHEBREMICHAEL, K.A.; GUNARATNA, K.R.; HENRIKSSON, H.; BRUMER, H.; DALHAMMAR, G.A. 2005. A simple purification and activity assay of the coagulant protein from Moringa oleifera seed. Water Res. 39:2338-2344.

18. GOYCOOLEA, F.; CÁRDENAS, A. 2004. Pectins from Opuntia spp.: a short review. J. Profess. Assoc. Cactus Develop. 5:17-29.

19. GONZÁLEZ, G.; CHÁVEZ, M.; MEJÍAS, D.; MAS Y RUBÍ, M.; FERNÁNDEZ, N.; LEÓN DE PINTO, G. 2006. Use of exudated gum produced by Samanea saman in the potabilization of the water. Rev. Técn. Ing. U. Zulia. 29(1):14-22.

20. GRAHAM, N.; GANG, F.; FOWLER, G.; WATTS, M. 2008. Characterization and coagulation performance of a tannin-based cationic polymer: A preliminary assessment. Coll. Surf. A: Physicochem. Eng. Aspects. 327(1):9-16.

21. HAAROFF, J.; CLEASBY, J. 1988. Comparing aluminum and iron coagulants for in line filtration of cold waters. J. Am. Water Works Assoc. 80:168-175.

22. JEON, J.R.; KIM, E.J.; KIM, Y.M.; MURUJESAN, K.; KIM, J.H.; CHANG, Y.S. 2009. Use of grape seed and its natural polyphenol extracts as a natural organic coagulant for removal of cationic dyes. Chemosph. 77:1090-1098.

23. KIELY, G. 1999. Ingeniería ambiental. Fundamentos, entornos, tecnologías y sistemas de gestión. Vol. II. España. McGraw-Hill. 1331p.
24. LEE, S.H.; LEE, S.O.; JANG, K.L.; LEE, T.H. 1995. Microbial flocculant from Arcuadendron SP-49. Biotechnol. Lett. 17:95-100.

25. MATSUHIRO, B.; LILLO, L.; SÁENZ, C.; URZÚA, C.; ZÁRATE, O. 2006. Chemical characterization of the mucilage from fruits of Opuntia ficus indica. Carbohydrate Polymer. 63:263-267.

26. MCCARTHY, J.F.; ZACHARA, J.M. 1989. Subsurface transport of contaminants. Environ. Sci. Technol. 23(5):496-502.

27. MATILAINEN, A.; VEPSÄLÄINEN, M.; SILLANPÄÄ, $M$. 2010. Natural organic matter removal by coagulation during drinking water treatment: A review. Adv. Colloid Interface Sci. 159:189-197.

28. MEDINA-TORRES, L.; BRITO-DE LA FUENTE, E.; TORRESTIANA-SÁNCHEZ, B.; KATTHAIN, R. 2000. Rheological properties of the mucilage gum (Opuntia ficus indica). Food Hydrocoll. 14:417-424.

29. MILLER, R.G.; KOPFLER, F.C.; KELTY, K.C.; STOBER, J.A.; ULMER, N.S. 1984. The occurrence of aluminium in drinking water. J. Am. Water Workers Assoc. 76:84-91.

30. MILLER, S.M.; FUGATE, E.J.; CRAVER, V.O.; SMITH, J.A.; ZIMMERMAN, J.B. 2008. Toward understanding the efficacy and mechanism of Opuntia spp. as a natural coagulant for potential application in water treatment. Environ. Sci. Technol. 42:4274-4279.

31. MUYUBI, S.A.; EVINSON, L.M. 1995 Optimizing physical parameters affecting coagulation of turbid water with Moringa oleifera seeds. Wat. Res. 29(12):26892695.

32. NDABIGENGESERE, A.; NARASIAH, K.S.; TALBOT, B.G. 1995. Active agent and mechanism of coagulation of turbid waters using Moringa oleifera. Wat. Res. 29(2):703-710.

33. OKUDA, T.; BAES, A.U.; NISHIJIMA, W.; OKADA, M. 2001. Isolation and characterization of coagulant extracted from Moringa oleifera seed by salt solution. Wat. Res. 35:405-410.

34. ÖZACAR, M.; SENGIL, I.A. 2000. Effectiveness of tannins from valonia as a coagulant aid for dewatering of sludge. Wat. Res. 34(4):1407-1412. 
35. ÖZACAR, M.; SENGIL, I.A. 2003. Evaluation of tannin biopolymer as a coagulantaid for coagulation of colloidal particles Colloids and Surfaces A. Physicochem. Eng. Aspects. 229:85-96.

36. PRADO, H.; MATULEWICZ, M.; BONELLI, P.; CUKIERMAN, A. 2011. Potential use of a novel modified seaweed polysaccharide as flocculating agent. Desalin. 281:100-104.

37. PRITCHARD, M.; MKANDAWIRE, T.; EDMONDSON, A.; O’NEILL, J.G.; KULULANGA, G. 2009 Potential of using plant extracts for purification of shallow well water in Malawi. Phys. Chem. Earth. 34:799-805.

38. PRITCHARD, M.; CRAVEN, T.; MKANDAWIRE, T.; EDMONDSON, A.S.; O'NEILL, J.G. 2010. A comparison between Moringa oleifera and chemical coagulants in the purification of drinking water - An alternative sustainable solution for developing countries. Phys. Chem. Earth. 35:798-805.

39. RODRÍGUEZ M., J.P.; LUGO U., I.P.; ROJAS C., A.V.; MALAVER C., C. 2007. Evaluación del proceso de la coagulación para el diseño de una planta potabilizadora. Umbral Científico. 11:8-16.

40. ROMERO, J. 2000. Calidad del Agua. Escuela Colombiana de Ingeniería. p.452-468.

41. SAAG, L.; SANDERSON, G.; MOYNA, P.; RAMOS, G. 1975. Cactasea mucilage composition. J. Sci. Food Agr. 26:993-1000.

42. SÁNCHEZ-MARTÍN, J.; BELTRÁN-HEREDIA, J.; SOLERA-HERNÁNDEZ, C. 2010a. Surface water and wastewater treatment using a new tannin-based coagulant. Pilot Plant Trials. J. Environ. Managem. 91:2051-2058.

43. SÁNCHEZ-MARTÍN, J.; GONZÁLEZ-VELASCO, M.; BELTRÁN-HEREDIA, J. 2010b. Surface water treatment with tannin-based coagulant from Quebracho (Schipolsis balansae). Chem. Eng. J. 165:851-858.

44. SANGHI, R.; BHATTACHARYA, B.; SINGH, V. 2002. Cassia angustifolia seed gum as an effective natural coagulant for decolourisation of dye solutions. Green Chem. 4:252-254.

45. SANTOS, A.F.S.; LUZ, L.A.; ARGOLO, A.C.C.; TEIXRIRA, J.A.; PAIVA, P.M.G.; COELHO, L.C.B.B. 2009. Isolation of a seed coagulant Moringa oleifera lectin. Process Biochem. 44:504-508.
46. ŠĆIBAN, M.; KLAŠNJA, M; STOJIMIROVIC, J. 2005. Investigation of coagulation activity of natural coagulants from seeds of different leguminose species. Acta Periodica Technol. 36:81-87.

47. ŠĆIBAN, M.; KLAŠNJA, M.; ANTOV, M.; ŠKRBIĆ, B. 2009. Removal of water turbidity by natural coagulants obtained from chestnut and acorn. Biores. Techn. 100:6639-6643.

48. SCHULTZ, C.R.; OKUN, D.A. 1992. Surface water treatment for communities in developing countries. John Wiley and Sons Inc. Intermediate Technology Publications, Grand Britain. 300p.

49. TRACHTENBERG, S.H.; MAYER, A. 1981. Calcium oxalate crystals in Opuntia ficus-indica (L.) Mill.: development and relation to mucilage cells-A Stereological analysis. Protoplasma, 109:271-283.

50. VARGAS CAMARENO, M.; ROMERO ESQUIVEL, L.G. 2006. Aprovechamiento de algunos materiales en el desarrollo de coagulantes y floculantes para el tratamiento de aguas en Costa Rica. Tecn. Marcha. 19(4):37-41.

51. YANG, Y.C.; ABDUL-TALIB, S.; PEI, L.Y.; NIZAN ISMAIL, M.S.; AISAH ABD-RAZAK, SN.; MAHYUDDIN MOHD-MOHTAR, A. 2008. A study on cactus Opuntia as natural coagulant in turbid water treatment. Disponible desde Internet en: http://ptarpp2.uitm. edu.my/suhaimiabdultalib/fulltext/A\%20Study\%20 On\%20Cactus.pdf (con acceso 12/04/2012).

52. YIN, C.Y. 2010. Emering usage of plant-based coagulants for water and wastewater treatment. Process Biochem. 45:1437-1444.

53. YONGABI, K.A. 2004. Studies on the potential use of medicinal plants and macrofungi (lower plants) in water and wastewater purification. FMENV/ZERI Res. Centre. Abubakar Tafawa Balewa U. Bauchi. Nigeria. Disponible desde Internet en: http:www.botech.kth.se/ iobb/news/e-sem-05.html (con acceso10/04/2012).

54. ZHANG, J.; ZHANG, F.; LUO. Y.; YANG. H. 2006. A preliminary study on cactus as coagulant in water treatment. Process Biochem. 41:730-733.

Recibido: Agosto 14 de 2012

Aceptado: Enero 24 de 2013 